\title{
Ambigüedades en dos décadas de paradigma multiculturalista. Algunos elementos de la historia inmediata de los Afrocolombianos*
}

Ambiguities in two decades of the multiculturalist paradigm.
Elements of the immediate history of the 'Afro-colombians'

\author{
Ambiguidades em duas décadas de paradigma \\ multiculturalista. Alguns elementos da história imediata \\ dos Afro-colombianos
}

\footnotetext{
* Estudiante de doctorado en Filosofía de la Universidad del Valle. Licenciado en Historia y con estudios de Maestría en Filosofía en la misma Universidad. Actualmente, profesor e investigador del Centro de Estudios Afrodiaspórico (CEAF) en la Universidad Icesi. También, ha estado vinculado como profesor e investigador en la Universidad del Valle, la Universidad Javeriana de Cali y la Universidad del Pacífico en Buenaventura. Sus trabajos de investigación han girado en torno al análisis dela realidad de la población afrodescendiente. Correo electrónico:luisva5@yahoo.com

** Este artículo de reflexión es producto de las investigaciones "De Buenaventura a Cali: discursos sobre la cultura y la identidad" realizada en 2012, así como de "La invención del 'negro' y del 'afro'” llevada a cabo entre 2009-2010 en la Universidad del Valle. Una versión preliminar de este artículo puede encontrarse como el número 2 de la Serie de Documentos de Trabajos del CIES del 2014, con el título "Los afrocolombianos entre avances, confusiones y retrocesos en dos décadas de paradigma multiculturalista”. Artículo recibido el 18/02/2015 y aceptado el 07/07/2015.
} 



\section{Resumen}

Abstract

Resumo

La historia inmediata de los afrocolombianos ha estado marcada por una serie de avances, confusiones y retrocesos; todo un devenir que al ser analizado de manera detenida deja ver la ambigüedad presente en el paradigma multiculturalista. Paradigma desde donde se ha pretendido organizar la sociedad de tal forma que se haga justicia a las "minorías" históricamente maltratadas por la discriminación cotidiana y estructural existente en la sociedad colombiana. En este sentido, en este artículo se pretende contrastar lo expresado en la Constitución política de 1991, la Ley 70 de 1993, material bibliográfico pertinente al tema y la realidad de los afrocolombianos, lo que permite concluir que las bondades conquistadas por los afrocolombianos tras estas dos décadas de multiculturalismo no se comparan con las pérdidas que están afrontando. Se argumenta que si bien las políticas afirmativas, el discurso del reconocimiento ha sido tolerado y respetado por unos sectores de la sociedad colombiana, un gran número de colombianos siguen teniendo una actitud negativa hacia los afrocolombianos.

PALABRAS CLAVE:

Multiculturalismo | afrocolombianos | negros | autofagia | biodiversidad

The immediate history of the Afrocolombians has been marked by a series of advances, confusions and regressions. All of a becoming that at being analyzed in a carefully way, it reveals the ambiguity present in the multiculturalist paradigm. Paradigm from where it has been pretended to organize the society; such form that it does justice for the 'minorities' historically badly treated by the daily discrimination and structural existing in the Colombian society. In this sense, this article aims to contrast what was stated in the 1991 Colombian Constitution, the Law 70 of 1993, relevant bibliographic material to the issue and the reality of Afro-Colombians, leading to the conclusion that the benefits conquered by the Afro behind these two decades of multiculturalism do not compare with the losses they are facing. It is argued that while affirmative policies, speech recognition has been tolerated and respected by some sectors of Colombian society, a large number of Colombians still have a negative attitude to the Afro-Colombians.

\section{KEYWORDS:}

Multiculturalism | afrocolombians | blacks | autophagy | biodiversity 
A história imediata dos afro-colombianos está marcada por uma série de avanços, confusões e retrocessos; todo um acontecimento que ao ser analisado cuidadosamente revela a ambiguidade presente no paradigma multiculturalista. Paradigma a partir do qual tem se procurado organizar a sociedade de tal forma que se faça justiça às "minorias" historicamente maltratadas pela discriminação cotidiana e estrutural existente na sociedade colombiana. Neste sentido, neste artigo se pretende contrastar o que está expresso na Constituição política de 1991, a Lei 70 de 1993, material bibliográfico pertinente ao tema e à realidade dos afro-colombianos, o que permite chegar à conclusão que as bondades conquistadas pelos afro-colombianos após estas duas décadas de multiculturalismo não se comparam com as perdas que estão enfrentando. Argumenta-se que, se bem que as políticas afirmativas, o discurso do reconhecimento tem sido tolerado e respeitado por uns setores da sociedade colombiana, um grande número de colombianos continua tendo uma atitude negativa com relação aos afro-colombianos.

\section{PALAVRAS CHAVES:}

Multiculturalismo | afro-colombianos | negros | autofagia | biodiversidade 


\section{Introducción}

Existen referentes nacionales e internacionales que hacen parte del frenesí de análisis, investigaciones, reflexiones y habladurías que hoy circulan en el contexto académico en torno a la historia inmediata de los afrocolombianos. Entre ellos se pueden nombrar la Constitución de 1991, la Ley 70 de 1993, la "III Conferencia Contra el Racismo, la Discriminación Racial, la Xenofobia y Todas las Formas Conexas de Intolerancia" celebrada en Durban entre el 31 de agosto y el 7 de septiembre del año 2001, y la declaración del 2011 como "Año Internacional de los Pueblos de Ascendencia Africana" por la Organización de Naciones Unidas. Lo importante de estos referentes es que en muchas ocasiones han permitido que los procesos organizativos que se gestan en las comunidades de base, develen la ambigüedad entre la teoría y la práctica, el discurso y la cruda realidad por la que atraviesan los afrodescendientes en Colombia. Dicho esto, los lectores tendrán en este escrito una reflexión histórico-filosófica acerca de los avances, confusiones y retrocesos por donde el devenir de la historia inmediata de los afrocolombianos ha transitado, con énfasis especial en el territorio del Pacífico colombiano. Reflexión con la que se busca proponer una mirada compleja de la historia reciente de los afrocolombianos, distante de aquella mirada simplista y polarizada que todo lo reduce o al triunfalismo apologético o a una postura derrotista paralizante, dos extremos que no permiten sopesar ni analizar de manera detenida la realidad por la que han caminado los hijos de la diáspora africana en Colombia.

\section{Una nueva tendencia dentro de la agenda política y el interés científico social}

En términos de avances en el campo de las ciencias sociales y las humanidades dentro de la academia colombiana, desde 1991 hasta el momento, se ha consolidado la tendencia del "negro" como tema de estudio, lo que ya no es una novedad sino una fuerte tendencia que dependiendo de la calidad de la reflexión, los marcos teóricos, el nivel de compromiso del investigador, puede fortalecerse o perder su rigurosidad y convertirse en una moda más que irrumpe en la academia.

La consolidación de esta tendencia dentro de las ciencias sociales y las humanidades en Colombia tiene tras de sí una larga historia de lucha por posicionar al "negro" como el otro reconocido. En esta fatigosa lucha han contribuido los trabajos de hombres y mujeres como Agustín Codazzi, Virginia Gutiérrez de Pineda, Jaime Jaramillo Uribe, Germán Colmenares, Jorge Palacios Preciado, Aquiles Escalante, Jorge Artel, Nina Sánchez de Friedemann, Jaime Arocha, Arnoldo Palacios, Jasques 
Aprille, Francisco Zuluaga, Mario Diego Romero, Manuel Zapata Olivella, Alfredo Vanín, entre otros. Todos estos pensadores, investigadores, intelectuales, que antes de los 90 se atrevieron de una u otra forma a romper con ciertos convencionalismos académicos que circunscribían la cientificidad y el interés humanístico en dos matrices culturales: la herencia europea presente en la cotidianidad política, económica y sociocultural de la nación, y la herencia indígena que pese a su calidad de marginalizada es constitutiva de la personalidad de la nación colombiana. Trasgrediendo este convencionalismo académico, estos pensadores, investigadores e intelectuales fueron posicionando al "negro" como un actor digno de ser estudiado y visibilizado por humanistas y cientistas sociales.

De forma paralela a este avance, en el mundo académico se fueron dando las reivindicaciones políticas de las comunidades de base; como fruto de las exigencias elaboradas por los "negros" durante su existir diaspórico en Colombia. En 1991 se promulgó la nueva Constitución Política, sustentada en un paradigma multicultural ${ }^{1}$ de corte neoliberal. Esta nueva Constitución significó un gran avance en términos jurídicos, puesto que la población "negra" empieza a gozar de un marco legal que se refuerza con la Ley 70 de 1993 que les reconoce como un otro constitutivo de la personalidad de la nación. ${ }^{2}$ Reconocimiento que requiere de una protección especial hacia sus territorios, lenguas y prácticas culturales tradicionales, mediante el etno-desarrollo, la etno-educación y todas las políticas públicas pertinentes (acciones afirmativas) que permitan a las comunidades "negras" ser reparadas por el daño cometido durante los siglos de explotación en que estuvieron sometidas. Es en este sentido que las ciencias sociales y las humanidades han tenido una apertura epistemológica y un interés investigativo hacia los temas del devenir afro, del reconocimiento legal expresado en acciones afirmativas, como la ley antidiscriminación 1482 de 2011, que muestran los avances en la historia inmediata de los afrocolombianos.

\footnotetext{
1. Por multiculturalismo entiendo el paradigma político liberal que en teoría busca dar reconocimiento a las distintas culturas que habitan dentro de un Estado. Este reconocimiento parte de revaluar el trato que tradicionalmente el Estado liberal ha dado a sus habitantes, que en busca de la imparcialidad los considera como individuos, desconociendo que los individuos son seres humanos que necesitan la protección de ciertos contextos comunitarios para poder llevar una vida digna. Para subsanar sus tradicionales falencias, el Estado liberal crea un marco legal especial que supone tener el poder para cambiar las prácticas discriminatorias que mantienen en condición de inferioridad a las culturas "minoritarias".

2. Si bien, a partir de 1991 se habla a favor del multiculturalismo y la protección de la diferencia, la Constitución de 1991 hace referencia textual a las comunidades indígenas como sujetos de la legislación. La Ley 70 de 1993 introduce a la comunidad afrocolombiana como actor político y social (Erazo Gómez, 2012).
} 


\section{Dos formas discursivas ${ }^{3}$ en pugna}

No obstante, en medio del avance que significó la creación del marco legal multiculturalista representado en la promulgación de la Constitución de 1991 y la Ley 70 de 1993, se presenta una gran confusión: ¿Cómo deben ser llamados: afrodescendientes, afrocolombianos o "negros"? Para muchos un interrogante que pretende introducir en la agenda política y el debate académico un problema semántico irrelevante; para otros, una pregunta importante y reveladora: ¿en qué sentido lo es?

En la medida en que pone de frente el análisis de la invención de estos dos términos, concebidos no como meras palabras sino como formas discursivas ${ }^{4}$, entendiendo discurso en el sentido expresado por Foucault (1991): términos que eclosionan como resultado del vínculo entre saber y poder. Dicho esto, es pertinente preguntar por el conjunto de teorías científico-filosóficas y el conjunto de acciones o prácticas políticas que han llenado de contenido los momentos de nacimiento de cada uno de estos términos, lo cual evidencia que el debate presente en el interrogante ¿cómo deben ser llamados: afrodescendientes, afrocolombianos o "negros"? no es una cuestión que se reduce a lo semántico, pues la tensión generada por el uso del término "afro" responde a unos procesos de reivindicación con efectos no solo en el plano social, sino también en el plano epistemológico.

Ahora bien, para afrontar esta confusión, La invención del 'negro' y el 'afro' (Valencia, 2010) señala varios aspectos relevantes sobre este asunto: explora el nacimiento del "negro" y aporta elementos para refutar la tesis según la cual el menosprecio hacia el africano por su color de piel surge en la Modernidad, a partir de prácticas como la trata negrera y la esclavización de los africanos para el trabajo en las plantaciones, por una lado; por otro, emerge de teorías científico-filosóficas, como la supuesta existencia de razas y seres por naturaleza inferiores a otros, a las que era legítimo explotar y forzar a trabajar hasta el límite de sus fuerzas físicas y espirituales. Tesis como esta, sostenida por el sociólogo peruano Aníbal Quijano (2000), fueron refutadas en la medida en que demostraron que el menosprecio hacia los africanos es anterior a la Modernidad, asociado a factores como el simbolismo cromático (lo blanco y lo negro) de lo sagrado y lo profano, lo bueno y lo malo, presente en el mundo grecorromano y que en la Edad Media se refuerza de tal manera que lo blanco encarna en el europeo y lo negro en el africano. Un ejemplo lo da la mitología medieval que habla de monstruos y de gentes bestiales

3. Soy enfático en manifestar que entiendo por "negro" y "afro" dos formas discursivas, es decir, un conjunto de teorías y practicas desde donde se construye la realidad. Este énfasis permite comprender la noción de invención, pues inventar, para nuestro caso, no se reduce a la falsedad, la mentira, sino a la creación desde el poder de las teorías y las prácticas políticas, lo que equivale a comprender estos términos en tanto construcciones sociales.

4. Al respecto, la obra de Said (1996) se constituye en un buen ejemplo, puesto que este autor hace un cuidadoso análisis del orientalismo en tanto discurso, es decir, en tanto teoría y práctica que además de crear un conocimiento prejuicioso de Oriente, tiene la capacidad de crear la realidad que parece describir. 
que viven en Etiopía y tienen piel oscura; es posible rastrear esta violencia simbólica en los relatos de Marco Polo, quien al ver a los habitantes de Zanzíbar expresa:

Son todos idólatras; tienen rey y lenguaje propio; no pagan tributo a nadie. Las gentes son grandes y gruesas, aunque en verdad no son grandes en relación a lo gordos que son; porque os digo que son tan gordos y membrudos que, si tuvieran la talla en proporción, parecerían desde luego gigantes. Y os digo que son desmesuradamente fuertes, porque llevan la carga de cuatro hombres que no fueran de esta isla; y no es maravilla, porque os aseguro que cada uno come la ración de cinco hombres de otra comarca. Son completamente negros y van totalmente desnudos, salvo que cubren su naturaleza. Y hacen muy bien porque las tienen muy gruesas, vil e incluso horrible de ver. Tienen los cabellos tan crespos que apenas se los puede alizar con agua. Tienen tan grande la boca, la nariz tan chata y respingada como la de los monos y las aletas de la nariz tan espesa que es maravilla. Tienen las orejas vastas, y los labios tan gruesos, vueltos hacia fuera, y los ojos tan grandes y tan inyectados que es cosa horrible, porque quien los viera en otra comarca diría que son diablos (Polo, 2000: 508).

La violencia simbólica hacia los africanos en la Edad Media evidencia varias aspectos: en primer lugar, demuestra que la invención del "negro" no nace en la Modernidad; en segundo lugar, revela la existencia de un problema relacionado con el marco interpretativo, en tanto que la mayoría de trabajos surgidos con el boom del paradigma multiculturalista consideran que el factor determinante para explicar la visión negativa y deshumanizante hacia el africano y sus descendientes diaspóricos, es económico; olvidando que el factor cultural -la violencia simbólica- ha jugado un papel relevante dentro del desarrollo del "negro"; y en tercer lugar muestra cómo con la Modernidad se consolida la invención del "negro" en tanto forma discursiva, gracias a los argumentos esgrimidos por los saberes de las ciencias sociales, que al presentarse como objetivos y como nueva fuente dadora de la verdad, crearon el discurso de la raza funcional a la explotación capitalista.

Todos estos aspectos permiten comprender la gran producción bibliográfica en torno al devenir de los afrodescendientes, en general, y de los afrocolombianos, en particular, y analizar el término "negro" como un discurso asociado desde sus inicios con el irrespeto, el desprecio, la deshumanización, la violencia simbólica, la explotación y la esclavización del africano. De esta manera, cabe preguntarse por qué en estos años de consolidación del paradigma multiculturalista hay quienes con vehemencia defienden la validez de este término como autodenominación.

En primera instancia, debe decirse que esta defensa es comprensible si se observa cómo durante siglos se configuró una pedagogía del maltrato y la cosificación, de sol a sol se martillaba en la cabeza del africano y sus descendientes diaspóricos la idea de que eran unos seres inferiores, explotados, dependientes, feos, brutos. Es de esperar, como bien lo estudió Fanon (1973), que en los contextos de colonización el africano y sus des- 
cendientes diaspóricos sufrieran daño sicopatológico, y que su conciencia e identidad terminaran asumiéndose como un objeto fobiógeno, angustiógeno. De ahí la aceptación del término "negro" en tanto autodenominación y autoidentificación.

No obstante, más allá de la presión sicológica a la que estuvieron sometidos los africanos y sus descendientes diaspóricos siempre existió, y existe aún, el margen para empezar procesos de fortalecimiento de la conciencia colectiva e individual. Un acto de rebeldía, de resistencia y de re-existencia ${ }^{5}$, en el que muchos impulsan un proceso de transvaloración del término negro: en una mezcla de orgullo y de digna tozudez han decidido cambiar el valor, el sentido y el significado de lo negro y del "negro", para expresar y manifestar que lo negro es bello, que el "negro" es sinónimo de laboriosidad, creatividad, entrega, sacrificio, fortaleza, valentía y alegría.

Este juego transvalórico que afecta positivamente la representación social de los afrodescendientes, surge de lo que en la academia hombres como Foucault (1991) y Nietzsche (2000) explicaron bajo el nombre de reflexión genealógica ${ }^{6}$ : una mirada crítica de la historia donde los acontecimientos más que responder a las dinámicas de origen y continuidad, pasan a ser vistos como irrupciones, rupturas, invenciones creadas bajo las necesidades del contexto. La transvaloración o resignificación de la representación social del "negro" es resultado de procesos políticos, sociales y culturales de la reivindicación hecha por los afrodescendientes.

Ahora bien, se comprende el porqué de la defensa del término negro como denominación y autodenominación por parte de muchas organizaciones e individuos que trabajan en procesos de reivindicación de comunidades afrodescendientes en Colombia. Sin embargo, es ilógica e inapropiada la resistencia de muchos a aceptar la validez del término afro (descendientes) como denominación y autodenominación, argumentando que es una imposición del blanco-mestizo, una suerte de eufemismo creado por este para redimirse del daño causado a los "negros" y una muestra de su incapacidad de aceptar el proceso de transvaloración de la representación social del "negro".

A estos detractores habría que recordarles que es en Norteamérica donde el prefijo afro cobra fuerza como autodenominación, cincelado bajo las exigencias y propuestas de diversos movimientos sociales, como el panafricanismo liderado por Edward Du Bois y Marcus Garvey; el movimiento de lucha por los derechos civiles liderado por hombres como Martin Luther King, Malcolm X y las Panteras Negras. En este sentido, las palabras de Malcolm, pronunciadas el 16 de febrero de 1955 en Nueva York, son elocuentes:

5. Re-existencia: capacidad que los afrodescendientes han demostrado para reinventar a diario su existir más allá de los estrechos márgenes dejados por la voluntad de poder de instituciones y grupos hegemónicos.

6. La referencia a Foucault y Nietzsche se hace solo para recordar a dos grandes representantes del método genealógico; no para evidenciar referentes filosóficos pertenecientes al debate "negro" o "afro", pues no es el tema de interés en las obras señaladas de estos autores. 
Muchos nos engañamos a nosotros mismos creyendo que los afroamericanos somos los que nos encontramos aquí en Estados Unidos. América consiste en Norteamérica, Centroamérica y Sudamérica. Cualquier persona de ascendencia africana en Sudamérica es afroamericana. Cualquier en Centroamérica con sangre africana es afroamericana. Cualquiera que vive aquí en Norteamérica, incluso en Canadá es afroamericano si es de ascendencia africana. Incluso los que viven en el Caribe son afroamericanos (...) los afroamericanos comprendemos el gran número de personas del hemisferio occidental desde el extremo sur de Sudamérica hasta el extremo norte de Norteamérica que -si se investiga la historia de estos pueblos- tenemos una herencia común y un origen común (Malcolm, 1993: 175).

Aunque en este caso el prefijo afro aparece dentro de una dimensión continental, es una evidencia suficiente para refutar la afirmación según la cual afro, afrodescendiente, es una imposición del blanco-mestizo. En esta misma línea, también habría que mencionar otros asuntos: primero, el término afro (descendiente) como forma discursiva es el resultado de una serie de luchas que los afrodiaspóricos han desplegado a lo largo de su trayectoria en los continentes en donde se concretó su dispersión; segundo, afro es una forma discursiva desde donde unos seres humanos se han autodefinido de manera positiva, digna; tercero, afro (descendiente) es una forma discursiva motivada no por el odio o la venganza, sino por dos aspectos: la voluntad de vida $^{7}$ y la re-existencia; en cuarto lugar, y apoyados en los planteamientos de Césaire (2006), el discurso afro se constituye a partir de una unidad cultural conformada por una doble solidaridad: una solidaridad horizontal producida por la situación colonial o semicolonial, y otra solidaridad vertical que proviene de la unidad primera de la civilización africana; de la cual se diferenciaron toda una serie de culturas, deudoras de ella en grados diversos de esta civilización.

Estas cuatro formas de entender el discurso afro en estos momentos de consolidación del paradigma multiculturalista se han configurado gracias al diálogo entre planteamientos teóricos como el Panafricanismo (y su vertiente la Afrocentricidad), la Negritud, la Teoría Crítica, la Ética de la Liberación, los aportes de intelectuales como Fanon y la versión latinoamericana de los Estudios Culturales encarnada en el grupo Modernidad-Colonialidad; planteamientos que en líneas generales han posibilitado una lectura crítica no convencional de la cultura, el colonialismo, el capitalismo y su devenir histórico, y del lugar que ocupan en la historia (y en el presente) los indígenas, las mujeres, los afrodescendientes, los campesinos y la clase obrera.

Por otra parte, al entendimiento y difusión del discurso afro en los últimos años ha coadyuvado la realización de la III Conferencia Mundial contra el Racismo, la Discri- 
minación Racial, la Xenofobia y Todas las Formas Conexas de Intolerancia, realizada en Durban entre el 31 de agosto y el 7 de septiembre de 2001. Esta conferencia, como se indicó en La invención del 'negro' y el 'afro':

(...) fue sin duda alguna el momento clave para la articulación global de todos los esfuerzos que han respaldado el discurso "afro" desde décadas atrás en diversos contextos. Durban sirvió como indicativo a través del cual se puede apreciar la manera en que el discurso "afro" está en sintonía con las problemáticas actuales, puesto que en dicha conferencia los países miembros de la ONU tuvieron que dialogar y proponer medidas para combatir las formas actuales y complejas en que se presenta la discriminación y la exclusión en el mundo entero, lo cual evidenció que la herida producida por el colonialismo y la trata negrera continúa vertiendo sangre.

Ante la permanencia histórica de estos problemas, la Asamblea General de las Naciones Unidas convocó en 1998 a Estados, organizaciones internacionales, organizaciones no gubernamentales regionales para que en Durban dialogaran acerca de las diversas medidas convenientes para combatir el racismo, la discriminación racial, la xenofobia y las formas conexas de intolerancia. Entre las medidas surgidas se pueden citar las siguientes:

El reconocimiento de las acciones afirmativas ${ }^{8}$ como mecanismo para eliminar los niveles de injusticia social que padecen aquellos grupos históricamente maltratados (Valencia, 2010: 126-127).

En este sentido, el significado político de Durban pasa por evidenciar el giro lingüístico de "negro" a afrodescendiente como categoría identitaria para hablar de las personas que conforman la diáspora africana derivada de la trata negrera. Dicho significado también pasa por ser una plataforma intercontinental de gran peso, desde donde se pretendió reforzar los marcos legales que convierten a los afrodescendientes en ciudadanos plenos y sujetos internacionales de derechos, dignos de ser reparados y protegidos. Tal vez estos significados son los que motivaron las palabras del líder afro uruguayo Romero Rodríguez:

A ella [III Conferencia Mundial Contra el Racismo, la Discriminación Racial, la Xenofobia y las Formas Conexas de Intolerancia] entramos negros y salimos afrodescendientes.

Con identidad... Para mí, hombre viejo de la historia de mi país, es el hecho más importante en la presencia del negro en la historia de América Latina (Anton et al., 2009: 20).

8. Por acciones afirmativas, también pueden ser entendidas aquellas políticas públicas destinadas al incremento de la representación de las minorías en las áreas de empleo, educación y demás actividades, económicas y culturales, de las que por diversas razones han estado históricamente excluidas. 


\section{La biodiversidad en retroceso}

Estos son algunos de los avances y de las confusiones que los afrocolombianos han experimentado en estas dos décadas de constitucionalismo multiculturalista. En cuanto a los retrocesos se pueden señalar dos de suma importancia: la destrucción de la biodiversidad y la autofagia de los grupos y las organizaciones étnico-territoriales.

Resulta paradójico que en plena consolidación del multiculturalismo en Colombia, su biodiversidad sea progresivamente arrasada, esto indica que paralelas a las bondades de las políticas públicas multiculturalistas, traducidas en aspectos como titulación de territorios colectivos y becas condonables, corren simultáneamente problemáticas como el aniquilamiento de la biodiversidad.

Por biodiversidad se entiende la existencia de un sinnúmero de ecosistemas dentro de un territorio; ecosistemas compuestos por una gran variedad de flora, fauna, minerales y grupos humanos con diferentes expresiones y prácticas culturales, todos coexistiendo de manera interdependiente. Los expertos en ciencias naturales y en ciencias sociales consideran que la región con mayor biodiversidad en Colombia es la región del Pacífico.

El discurso oficial se enorgullece de esta biodiversidad y la considera una riqueza que debe ser protegida y aprovechada de manera sostenible. Para ello, sobre el marco de la Ley 70 de 1993, que protege a los grupos étnicos de la región del Pacífico, el Estado ha creado una serie de leyes, normas que regulan la actividad minera con miras a dar un buen uso de la biodiversidad. La Ley 99 de 1993 afirma que la política ambiental colombiana se guiará por lineamientos como la biodiversidad del país vista como patrimonio nacional y de interés de la humanidad que debe ser protegido prioritariamente y aprovechado en forma sostenible; destaca la protección especial de las zonas de gran producción acuífera y el paisaje, por ser patrimonio común. El Decreto 1320 de 1998 reglamenta la consulta previa con las comunidades indígenas y "negras" para la explotación de los recursos naturales dentro de su territorio.

Sin embargo, y pese a todo este marco legal que desde el candor de la letra escrita ama y protege la biodiversidad, en la complejidad de la práctica encontramos que el mismo Estado, en complicidad con el capital transnacional y un sinnúmero de ciudadanos nacionales inescrupulosos, destruyen poco a poco esta biodiversidad. Lo que permite decir que si bien en la teoría se habla de un paradigma multiculturalista, en la práctica se instituye el monoculturalismo.

Es la actividad minera misma la que permite sostener la idea de que en estos momentos de consolidación del paradigma multiculturalita, se atenta contra la biodiversidad existente en Colombia.

Los desastres que la actividad minera está causando sobre la biodiversidad existente en la región del Pacífico colombiano son el resultado de siglos de extracción de los metales preciosos en esta región, en detrimento de la calidad de vida de las comunidades 
afrocolombianas. Esta afirmación se sustenta en los hechos de la Conquista, cuando se descubrió la gran riqueza mineral de la región: el oro que conquistadores y colonizadores encontraron en la superficie arenosa de los ríos Dagua, Raposo, Anchicayá, Patía, Telembí, Barbacoas y San Juan de Micay, por mencionar solo algunos ríos de la costa suroccidental del Pacífico colombiano que aportaron insumos a la economía mercantilista colonial. Datos entregados por el Observatorio Pacífico y Territorio señalan que cerca del $25 \%$ del oro que circulaba en Europa provenía del actual territorio colombiano.

Por otra parte, si bien la actividad minera se estancó durante el siglo XIX como resultado de las múltiples guerras civiles en el país, para la primera mitad del siglo XX se volvió a reactivar, dentro de los esfuerzos de la élite por instalar una economía industrial: el oro y el platino extraídos en gran medida del Chocó, ayudaron a robustecer esta economía. En la década de los 70, en pleno auge del discurso desarrollista que planteaba la llegada del progreso y el fin de la pobreza material en el país, bajo la tutela de las potencias industrializadas como Estados Unidos.

La destrucción de la biodiversidad del Pacífico colombiano quedó magistralmente registrada en La Minería del Hambre de Aquiles Escalante (1971), que expone cómo en Condoto, Chocó, el Estado autorizó a la compañía minera neoyorkina Chocó Pacífico para realizar actividades extractivas; actividades que se tradujeron en la miseria de los mineros artesanales y de los pobladores nativos condoteños, en contraste con la opulencia de la compañía neoyorkina aliada con la oligarquía colombiana. Esta alianza constituyó unas relaciones asimétricas entre el Estado y las empresas mineras extranjeras apoltronadas en el territorio colombiano. El resultado no fue el progreso ni el fin de la pobreza material del Chocó, sino más bien deforestación, pobreza, hambre, saqueo y abandono estatal, entre otros males. Toda una situación que Escalante describió así:

\footnotetext{
Admira encontrar plasmada en Condoto la manera como los Estados Unidos fueron desplazando a Inglaterra como potencia de primer orden. Además, con la complicidad de las oligarquías colombianas, los capitalistas victoriosos se adueñaron por las buenas o las malas, de lo mejor del territorio chocuano. La Chocó Pacífico se dice dueña de las tres cuartas partes de las tierras del municipio de Condoto. En cambio las arcas municipales perciben anualmente la insignificante suma de \$13.752 por concepto de participación en el impuesto del oro (Escalante, 1971: 12).
}

Para estos tiempos de consolidación del paradigma multiculturalista, que suponen ser tiempos de respeto a los Derechos Humanos, de mayor conciencia crítica y sensibilidad social y ambiental hacia los grupos étnicos y su contexto, en realidad es poco prometedor el panorama para la existencia de la biodiversidad.

Lo sucedido durante el gobierno de Álvaro Uribe Vélez así lo evidencia. Según cifras aportadas por el Observatorio Pacífico y Territorio, durante los dos periodos de ese gobierno se entregaron a través de Ingeominas cerca de 9.000 concesiones mineras 
en Colombia. Muchas de estas avalaban actividades de minería extractiva en territorios protegidos por la legislación ambiental y la Ley 70 de 1993: páramos, territorios de propiedad colectiva indígena y afrodescendiente. Llaman la atención dos casos. El primero se relaciona con el otorgamiento de títulos mineros que el Gobierno Nacional concedió en el 2009 a la empresa minera Muriel Maining Corporation para explotar el cerro "Careperro", en territorio que a la luz de la Ley 70 de 1993 es propiedad colectiva indígena de los Embera; esta empresa realizó sus actividades mineras sin el debido proceso de consulta previa, libre e informada. El otro caso es el de Zaragoza-Buenaventura en torno al río Dagua, donde entre 2008 y 2010 se presentó una intensiva actividad minera a pequeña y mediana escala, supuestamente ilegal, que no contó con el debido proceso de las autoridades municipales o distritales ante las constantes denuncias. Según la fuente mencionada, alrededor de 430 retroexcavadoras ocuparon cerca de 11 kilómetros, y extrajeron aproximadamente 200 toneladas de oro. El daño ambiental y cultural fue enorme: es incalculable la cantidad de mercurio vertido al ambiente, el río perdió su tonalidad habitual, la fauna y la flora se redujeron sustancialmente; sumado a esto, las prácticas de prostitución y matoneo generaron problemas sociales que afectaron la convivencia humana en la región.

No es claro el panorama para la biodiversidad del Pacífico en el actual gobierno del presidente Juan Manuel Santos. Por un lado el presidente dice que su programa de la Locomotora Minera se sustenta en la idea de desarrollo sostenible, en que se incluyen todos los esfuerzos por hacer cumplir los requisitos legales necesarios para esta actividad; sin embargo, vale la pena tener presente el interrogante que plantea el columnista de la revista de la Corporación Arcoíris (Pérez, 2012), luego de escuchar las palabras del presidente durante el Primer Congreso Anual de Minería a Gran Escala realizado en Cartagena en febrero de 2013: "¿Qué le va a dejar efectivamente a la sociedad colombiana la 'locomotora minera' cuando se cumplan las metas de exportar 160 toneladas anuales de carbón y 93 toneladas anuales de oro? Me atrevo a responder que sólo el recuerdo de la biodiversidad." Ahora bien, frente a la figura de la locomotora otrora utilizada por el presidente Rafael Reyes, cuyo gobierno (1904-1909) ha sido catalogado por muchos historiadores como una dictadura moderada, se valió de este vehículo como símbolo del progreso:

En tiempos pasados fue la Cruz o el Corán, la espada o el libro, los que hicieron la conquista de la civilización; actualmente es la poderosa locomotora, volando sobre el brillante riel, respirando como un volcán, la que despierta a los pueblos al progreso, al bienestar y a la libertad (...) y a los que sean refractarios al progreso los aplasta bajo sus ruedas (Bushnell, 1996: 228).

La locomotora encarnó un vivo deseo de progreso que se correspondía con la lógica de instrumentalización, cosificación de la naturaleza, un desprecio por lo ancestral y lo tradicional entendido como obstáculo para el progreso: la industrialización. La locomotora encarna un afán de la élite dirigente por establecer reconciliaciones, pactos, 
negocios y tratados, que en ocasiones fueron indignantes para la conciencia colectiva de los colombianos. ${ }^{9}$ Esta figura, en estos tiempos de agenda política multiculturalista, representa un anacronismo.

Dado que la locomotora vuelve a ser presentada en el actual escenario político como símbolo de progreso y prosperidad; se espera que tras su invocación no estén el desprecio por lo étnico, los negocios indignantes para la conciencia colectiva, los tratados favorables para unos pocos pero desfavorables para la mayoría de los colombianos. En fin, se espera que la locomotora del presidente Juan Manuel Santos no considere que la biodiversidad del Pacífico colombiano sea refractaria a su libre andar y así decida aplastarla bajo sus ruedas.

\section{Problemas al interior de grupos étnicos y sus organizaciones}

Las consecuencias de carácter sicológico que el colonialismo capitalista y su esclavitud dejaron en la vida de los afrodescendientes han sido rigurosamente estudiadas por diversos académicos e intelectuales: Césaire (2006), Du Bois (2001), Fanon (1973), Memmi (1969), entre otros. Dada la recurrente referencia a estos autores al abordar estos temas, se hará énfasis en uno no tan referenciado, el académico e intelectual cubano Fernando Ortiz, quien de manera magistral supo expresar el peso de las consecuencias ya mencionadas en la vida de los "negros", como él les llamaba:

Permítanme de paso que os diga, aprovechando esta ocasión tan adecuada, que este tristísimo fenómeno de la autodenigración es perfectamente comprensible y discutible, conociendo la enorme presión con que las fuerzas dominadoras han aplastado durante siglos a los grupos humanos sometidos, y la tremenda y singular hostilidad del ambiente social contra quienes han tenido la desventura de que la subyugación le fuese agravada por lo imborrable y ostensible de su cutánea pigmentación. Por ello esa actitud negadora de su propia personalidad ha sido más frecuente y duradera en el negro (Ortiz, 1993: 139).

Este fenómeno negativista, así llamado por Ortiz, es una sicopatología colectiva que es producto de los siglos de aplastante dominación y presión social que tuvieron que soportar los afrodescendientes por su color. Sin embargo, negarse a sí mismo, alienarse, escapar de su negrura, buscar afanosamente ser parte de la ideología mestiza -blanquearse-: es el correlato de la autofagia que los grupos y las organizaciones étnico-territoriales afrodescendientes enfrentan hoy. 
Suena paradójico que en estos tiempos de consolidación del paradigma multiculturalista (en donde el marco legal hace al Estado garante de los procesos de etnoeducacion y etnodesarrollo, que apuntan al fortalecimiento de la identidad colectiva, del buen valorarse y del creer en sí mismo) la autofagia al interior de los grupos y las organizaciones étnica sea tan notoria. ¿Qué está sucediendo entonces?

En primera instancia, el carácter de los líderes, lideresas, académicos, políticos e intelectuales llamados a ser la vanguardia de los procesos reivindicatorios, ha demostrado ser de la misma "naturaleza" que la de cualquier otro grupo humano: susceptibles a hacer lo "bueno" y/o lo "malo", lo correcto y/o lo incorrecto, de acuerdo a los procesos de aprendizaje, a los contextos, a las experiencias vividas. En este sentido, si bien la historia ha mostrado que los afrodescendientes para subsistir en todos los lugares por donde los dispersó la trata negrera tuvieron que ser dignos, creativos, estratégicos, solidarios, fraternales; la historia crítica está mostrando que en estos momentos de fortalecimiento del capital empresarial nacional y trasnacional, la "naturaleza" y el carácter de muchos intelectuales, académicos, políticos, líderes y lideresas está en sintonía con la lógica propia del capitalismo actual: individualista, acumulativa de dinero y depredadora de la naturaleza.

En segunda instancia, ningún cuerpo, ninguna mente puede salir ilesa de siglos de dominación colonialista capitalista. Dos décadas de procesos de fortalecimientos de la conciencia colectiva no son suficientes para aprender a quererse, para des-alienarse, para creer en sí mismo y emprender procesos de cohesión social exitosos que permitan posicionar política, económica y socioculturalmente a los afrocolombianos. Dos décadas son poco para que se desvanezcan las taras, las aberraciones afectivas o las estructuras mentales que dejó el colonialismo.

No significa que la lucha de reivindicación de los afrocolombianos haya comenzado con la Constitución de 1991; se quiere apuntar al hecho de que, a la luz de unas condiciones supuestamente favorables, configuradas por el marco constitucional multiculturalista, no se puede alegremente juzgar a los afrocolombianos como desunidos, que no saben trabajar en equipo o incapaces de generar procesos de concientización o cohesión social.

Las políticas que el Estado ha creado para reparar a los afrocolombianos por tantos siglos de explotación están inmaduras. Tanto los funcionarios públicos como la sociedad en general apenas empiezan a digerirlas; no se puede esperar que estas políticas de la noche a la mañana cambien una estructura mental forjada durante siglos de colonialismo, en donde a millones de hombres se les inculcó el miedo, el complejo de inferioridad, el temblor, la genuflexión, la desesperación, el servilismo (Cesaire, 2006). Tener presente tal estado de inmadurez, permite salir al paso a las voces que de manera insensible dicen: “¿Por qué a los afro se les da tanto en estos tiempos?”

La autofagia que hoy sufren los grupos y organizaciones étnicas-territoriales es un fenómeno inducido por las fuerzas que históricamente han configurado la lógica ca- 
pitalista; sin embargo, para ser efectiva debió encontrar unos entes receptivos, que en este caso han sido las disposiciones de un sinnúmero de afrocolombianos inconscientes, alienados, poco comprometidos con los proyectos de vida de la comunidad, antípodas del tradicional comunalismo existente en las poblaciones del Pacífico.

"Muchos" de los afrocolombianos que dicen ser la vanguardia del movimiento, de los procesos organizativos étnico-territoriales, han demostrado ser incapaces de discernir el "orden" jerárquico de las necesidades de la comunidad y, dócilmente se dejan arrastrar por el orden que impone la alianza Estado-Capital empresarial, a todas luces interesado en exotizar la experiencia de vida de los afrocolombianos, para sustraer de las propuestas de las comunidades cualquier elemento revolucionario que genere un cambio estructural en beneficio de la comunidad. A cambio, se sigue vendiendo la idea de que los afrocolombianos necesitan, prioritariamente, bailes, festivales folclóricos, exposiciones gastronómicas, cursos de pintura y escritura.

Si bien la autofagia, entendida como rencillas y desacuerdos al interior de las comunidades de afrocolombianos, es "normal" en la medida en que el consenso y el disenso están a la orden del día de cualquier comunidad humana dinámica; ya que interpretar, valorar y actuar desde diferentes perspectivas subyace a toda común-unidad de seres humanos. La unidad, lo común, no tiene porqué conducir a la uniformidad. Lo que no es normal es que mientras una mayoría de seres humanos vive en condiciones indignantes, "muchos" de sus líderes y lideresas, académicos, intelectuales y políticos hablen por ellos de tal forma que sus realidades, sus exigencias, sus necesidades queden distorsionadas. Tampoco es normal que esta minoría contraiga negocios con el Estado y el capital empresarial donde sólo sean ellos, la vanguardia, los únicos beneficiados mientras la comunidad languidece.

Un ejemplo es la Universidad del Pacífico, una institución educativa de carácter étnico llamada a pensar la realidad del Pacífico colombiano y ayudar a brindar soluciones. Sin embargo, tras doce años de funcionamiento pasa por una profunda crisis: desde el 6 de septiembre de 2012 estudiantes y profesores se declararon en anormalidad académica, y junto con integrantes de consejos comunitarios y organizaciones juveniles bonaverenses se tomaron la sede administrativa, impidiendo el ingreso de los funcionarios por algo más de una semana; hasta que las autoridades policiales, en uso desmedido de la fuerza, los desalojaron. ${ }^{10}$

¿Qué ocasionó esta serie de hechos sin parangón en la historia de esta Universidad? Es posible asegurar que el fenómeno de la autofagia expresada en la progresiva actitud de las administraciones de turno de ir devorando dicha institución. Actitud que según las denuncias de los estudiantes y un número "digno" de profesores se desbordó durante el primer año de rectoría del Señor Florencio Cándelo Estacio. 
Según el comunicado del 7 de agosto del año en curso por el Colectivo Observatorio de Conflictos Ambientales, titulado: Asunto sentipensante a propósito de un traidor, la Universidad del Pacífico nace como un proyecto soñado y creado por poetas, artistas, científicos y reformadores. "Pero es monseñor Gerardo Valencia Cano el que empieza a pronunciarlo con mucha fuerza". La idea inicial de este proyecto universitario consistía en crear programas académicos al servicio de la población afro-indígena y mestiza con el fin de recrear lo local y fortalecerlo con el legado de los saberes científicos aplicados a las condiciones de la Realidad del Pacífico colombiano. No obstante, según este colectivo, una vez la idea es recogida por el representante a la cámara Omar Guido Barona y avalada por la ley 65 de 1988, financiada en la coyuntura de la Ley 70 de 1993, el mismo Barona y las administraciones siguientes hacen del proyecto regional universitario, un proyecto privado de bolsillo cuya corrupción llega a su límite con el actual rector Florencio Cándelo Estacio, aborrecido por los estudiantes por presuntas contrataciones y nombramientos ilegales, despidos injustificados, cierres injustificados de grupos de investigaciones, alianzas políticas y económicas para favorecer intereses particulares suyos y de terceros.

Casos como estos revelan la autofagia en los grupos, instituciones y organizaciones étnicas-territoriales afrocolombianas; fenómeno que no es patrimonio exclusivo de los afrodescendientes, pues se encuentra en todos los grupos humanos. Lo que aquí interesa es mostrar cómo en estas dos décadas de consolidación del paradigma multiculturalista, que supone mayor nivel de compromiso étnico, mayor respecto y protección a las tradiciones étnico-territoriales, se presenta la confluencia de fuerzas como la capacidad seductora y destructora del capital empresarial nacional y transnacional, el terror de los grupos al margen de la ley, la inconsciencia de ciertos miembros de la vanguardia afrocolombiana, la inoperancia y la falta de voluntad del Estado colombiano. Confluencia en que la autofagia señala que no todo ha sido avance en estos años de multiculturalismo.

\section{A modo de conclusión}

Todo indica que las bondades que han conquistado los afrocolombianos tras estas dos décadas de multiculturalismo constitucional, no se comparan con las pérdidas que afrontan. Si bien las políticas afirmativas y el discurso del reconocimiento del papel histórico de los afrocolombianos en la configuración de la nación han sido tolerados y respetados por unos sectores de la sociedad colombiana; un gran número de colombianos sigue teniendo una mirada negativa hacia los afrocolombianos. Ello se hace evidente en los chistes, insultos y dichos que en su diario vivir emiten tanto el ciudadano del común 
como los que gozan de mayor distinción, los ilustres senadores y los concejales. ${ }^{11}$ También se hace evidente en el resurgir de los grupos neonazis.

En este sentido, el hambre, el destierro, la miseria, la violencia física y sicológica, la explotación, el desempleo, el analfabetismo, las enfermedades crónicas que sufre la población afrodescendientes en estos tiempos de multiculturalismo, le dan la razón a un pensador como Zizek (2003), quien considera al multiculturalismo como la ideología del Capitalismo global en la medida en que las prioridades dentro de la agenda política quedan reducidas a la preocupación por unas identidades primordiales más que por el problema global que tiene que ver con la debilidad del Estado y el fortalecimiento de la acumulación capitalista liderado por las empresas privadas.

La puesta en escena de nuevos mecanismos de explotación, maltrato, discriminación, racismos y demás ignominias humanas, hace que el discurso multiculturalista sea apreciado, con justa razón, como una mera retórica, como un mero estribillo, ya que los resultados de las becas condonables, la titulación colectiva de territorios, los proyectos de etnoeducación y etnodesarrollo no se comparan con los resultados que vienen arrojando los negocios que el Estado realiza con el capital nacional y trasnacional $^{12}$, es decir, con las empresas nacionales e internacionales que motivadas por la acumulación de riqueza llevan a cabo sus actividades mineras, hoteleras y de cultivo de palma africana en los territorios que se suponen están protegidos por la Ley 70 y la normatividad ambiental.

Los resultados de estos negocios son muestra de la incapacidad del Estado para cumplir su función de salvaguardar la vida, los bienes y la honra de sus ciudadanos en estos tiempos de capitalismo global. Esta función queda en entredicho ante el poder del capital empresarial nacional y transnacional que pone al Estado en función de los intereses privados y no en función de los intereses de sus ciudadanos o de los grupos étnicos históricamente maltratados como los afrodescendientes.

\section{Referencias}

ANTON, J., BELLO, A., DEL POPOLO, F., PAIXAO, M., RANGEL, M. (2009). Afrodescendientes en América Latina y el Caribe: del reconocimiento estadístico a la realización de derechos: Santiago

\footnotetext{
11. A modo de ejemplo se pueden citar dos casos, uno es el del concejal de Bogotá Jorge Durán, que en agosto de 2012 expresó públicamente: "No ingresa nadie si no es funcionario o asesor de los concejales, no más, porque esto se nos está volviendo una merienda de negros.” El otro caso es el del diputado de Antioquia Rodrigo Meza, quien en un debate de la Asamblea, realizado el 8 de mayo de 2012 expresó: "la plata que uno le mete al Chocó es como meterle perfume a un bollo.”

12. De igual forma, hay que hacer referencia a la manera como diversas fundaciones, centros de investigación, ONG se sirven del contexto multiculturalista para instrumentalizar a las comunidades afrocolombianos.
} 
de Chile: Naciones Unidas.

BUSHNELL, D. (1996). Colombia una nación a pesar de sí misma. Bogotá, Colombia: Editorial Planeta.

CÉSAIRE, A. (2006). Discurso sobre el colonialismo. Madrid: Editorial Akal.

Colectivo Observatorio de Conflictos Ambientales (2012). Comunicado del 7 de agosto 2012: Asunto sentipensante apropósito de un traidor. Recuperado en: http://www.prodefensaunipa cifico.blogspot.com

DU BOIS, E. (2001). Las Almas del pueblo negro, Ciudad de la Habana, Cuba: Fundación Fernando Ortiz.

El espejismo de la minería. Video producido por el Observatorio Pacífico Territorio, sf, en: http:// www.pacificocolombia.org/

ERAZO GÓMEZ, A. (2012). "La Ley 70 de 1993 y la participación política de las comunidades negras”. En: Trans-pasando Fronteras, núm. 2, pp. 31-45. Cali: Universidad Icesi.

ESCALANTE, A. (1971). La Minería del Hambre, Medellín, Colombia: Ediciones Universidades Medellín.

FANON, F. (1973). Piel Negra, Mascaras Blancas. Buenos Aires: Editorial Abraxas.

FOUCAULT, M. (1991). Sujeto y poder, Bogotá, Colombia: Editorial Carpe Diem.

JAMESON, F Y ZIZEK, S. (2003). Estudios culturales. Reflexiones sobre el multiculturalismo. Buenos Aires, Argentina: Paidos.

MALCOLM X. (1993). Habla Malcolm X, Discursos, entrevistasy declaraciones. Nueva York, EE.UU.: Pathfinder.

MEMMI, ALBERT. (1969). Retrato del colonizado. Buenos Aires: Ediciones de la Flor.

NIETZSCHE, F. (200o). Genealogía de la moral, Bogotá, Colombia: Emfasar Editores.

ORTIZ, F. (1993). Etnia y sociedad. La Habana: Editorial de Ciencias Sociales.

PÉREZ, B. (s.f.). “Santos y su 'locomotora minera'”. En: http://www.arcoiris.com.co/2012/o8/o2 santos-y-su-locomotora-minera/

POLO, M. (2000). Libro de las maravillas. España: Edición de Ediciones.

QUIJANO, ANÍBAL. (1999). “iQue tal raza!”. En: Revista Ecuador Debate, núm. 48. Etnicidades e identificaciones. Quito: CAAP.

SAID, E. (1990). Orientalismo, Barcelona, España: editorial al Qibla ensayo IBN Jaldun libertarias. SAID, E. (1996). Cultura e Imperialismo, Barcelona, España: Editorial Anagrama.

VALENCIA, L. E. (2010). La invención del 'negro' y del 'Afro' [Tesis de Maestría]. Cali, Colombia: 
Universidad del Valle.

VALENCIA, L. E. (2014). "Los afrocolombianos entre avances, confusiones y retrocesos en dos décadas de paradigma multiculturalista". En:Documentos de Trabajo del CIES, núm. O2. Cali, Colombia: Universidad Icesi 